\title{
MENINGIOMA EM PLACA ATINGINDO TÔDA A CONVEXIDADE CEREBRAL
}

\author{
Gilrerto M. de Almeida * \\ JAMIL SALUM* \\ Cleusa M. Mantovani ** \\ Marcelo Marcondes *
}

Há muito tempo sabe-se que meningiomas podem invadir o crânio e provocar hiperostose. Às vêzes êstes tumores são múltiplos ou atingem grandes extensões. No presente trabalho registramos caso de meningioma em placa, excepcionalmente extenso, que ocupava tôda a convexidade cerebral, determinando hiperostose difusa.

J.E., 50 anos, sexo masculino, branco, brasileiro, internado em 15-12-965. Cêrca de 5 anos antes o doente começou a apresentar cefaléia frontal, vômitos esporádi$\cos$ e aumento do volume do crânio. Após dois anos surgiu déficit de visão. A sintomatologia piorou lentamente, instalando-se amaurose um ano antes da internação. Em 1962 o paciente teve convulsão, seguida de hemiparesia esquerda, transitória. Em 15-12-965 o quadro convulsivo repetiu-se, sendo o doente encaminhado ao Hospital das Clínicas. No exame de entrada constatou-se: inconsciência, hemiparesia esquerda, aumento do volume do crânio e palidez das papilas ópticas. A hemiparesia regrediu em três dias. O exame do líquido cefalorraqueano mostrou pressão normal. As radiografias do crânio mostraram espessamento de tôda a calota craniana, com substituição das tábuas ósseas por espiculas dispostas paralelamente. Em 3-2-966 foi feita arteriografia cerebral (fig. 1) via artéria carótida direita, tendo sido observado apenas aumento da vascularização dependente da carótida externa. Em 9-2-966, quando submetido à pneumencefalografia, o paciente teve convulsões, seguidas de inconsciência que persistiu até o óbito, em 20-2-966. Nos últimos dias o doentes apresentou quadro broncopneumônico.

Necropsia - Ao exame externo nota-se desproporção crânio-facial. Tôda a calota craniana apresenta-se espessada (cêrca de $2 \mathrm{~cm}$ de espessura), de consistência ligeiramente diminuida, não sendo possivel delimitar a diploe e as tábuas interna e externa. Parte da base do crânio também está comprometida. A duramáter da convexidade apresenta-se infiltrada, difusamente, por tecido tumoral esbranquiçado e friável que, em alguns pontos, adere ao plano ósseo. A implantação tumoral é também nítida na luz do seio longitudinal superior, na foice cerebral e nas porções anteriores e posteriores da base do crânio. O processo tumoral atinge os nervos ópticos, comprimindo-os. O periósteo da abóbada craniana, bastante espessado, está infiltrado pelo tecido tumoral. Não há invasão do encéfalo. o exame histológico do tumor mostra quadro de meningioma que, em algumas

Trabalho da Clinica Neurológica (Prof. Adherbal Tolosa), 19 Clínica Médica (Prof. Antonio B. Ulhôa Cintra) e Departamento de Anatomia Patológica (Prof. Constantino Mignone) da Faculdade de Medicina da Universidade de São Paulo: *Assistentes; ** Médico Residente. 

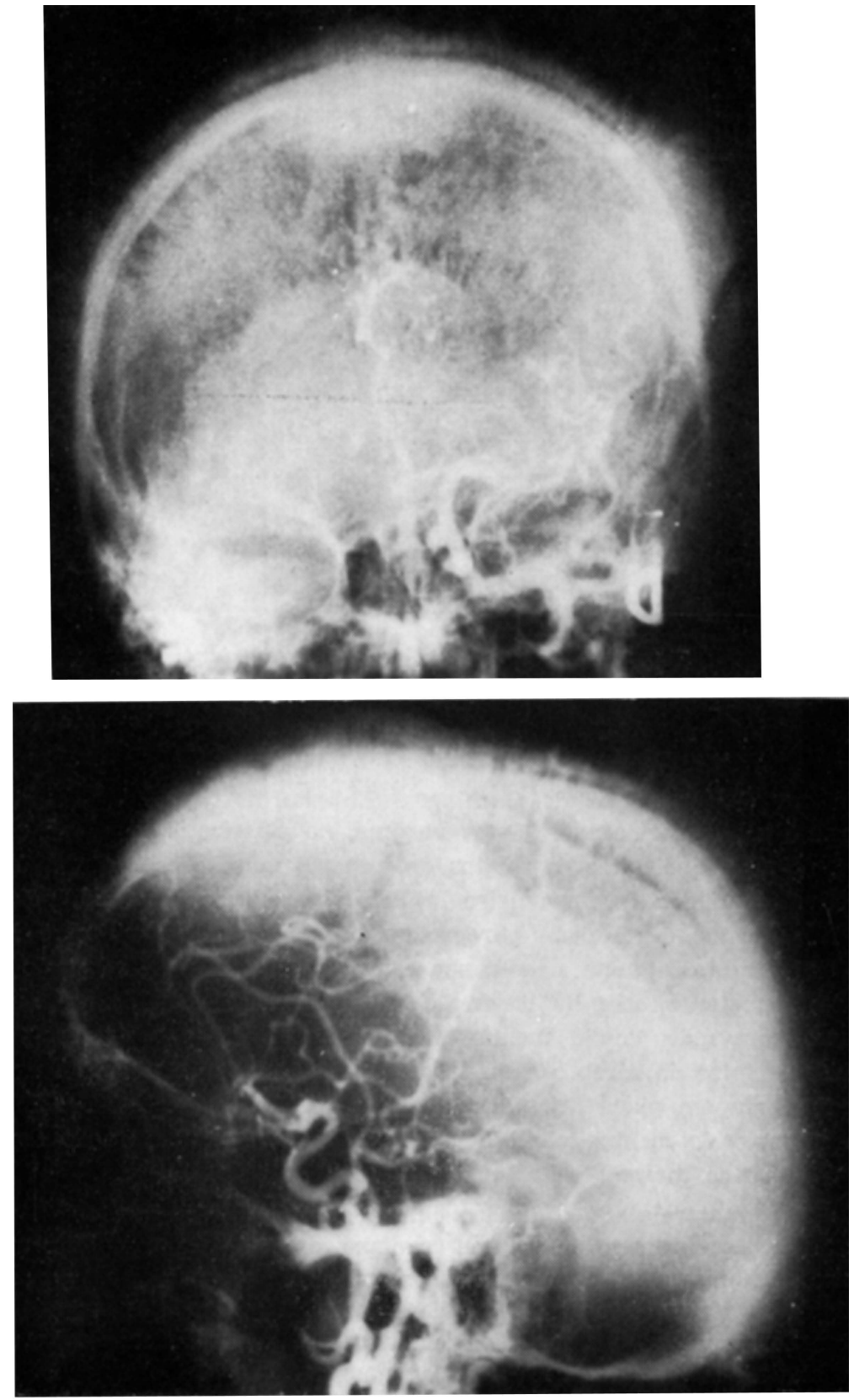

Fig. 1 -- J. E. Arteriografia em que se nota aumento da circulação dependente da artéria carótida externa, assim como a hiperostose difusa da calota, com disposição em espiculas paralelas. 
Jreas, apresenta-se do tipo fibroblástico e, em outras, do tipo sincicial. Em nenhum local existe aspecto histológico sugestivo de malignidade. $O$ tecido ósseo, nas partes espessadas, revela intensa hiperostose, com acúmulos de células meningiomatosas no espaco areolar. O periósteo também tem células tumorais.

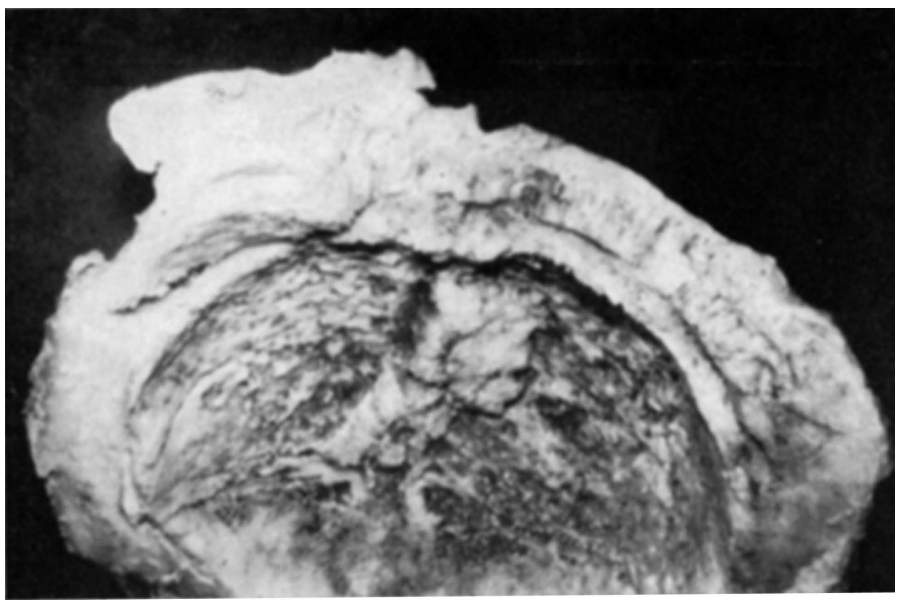

Fig. 2 - J.E. Aspecto da calota craniana.

\section{COMENTÁRIOS}

Na extensa casuística de Cushing e Eisenhardt 2 não há referência a caso semelhante ao relatado. Êstes autores, no clássico livro sôbre meningiomas, referem que entre os relatos de tumores volumosos nenhum é mais remarcável do que o do marinheiro Müller, apresentado em 1844, por Roemer. No desenho dêste doente, reproduzido no livro de Cushing e Eisenhardt, encontramos alguma semelhança com o aspecto apresentado pelo nosso paciente; entretanto, não há descrição do tumor. Almeida Lima ${ }^{1}$ que refere caso com mais de 30 meningiomas disseminados pela dura-máter da convexidade, foice do cérebro e tenda do cerebelo, também não tem exemplo de meningioma em placa atingindo tôda a convexidade cerebral. Obrador:s refere exemplo de meningiomatose calvária difusa, com infiltração do osso, mas não fornece maiores detalhes ou qualquer documentação.

No caso aqui relatado o quadro clínico caracterizou-se por cefaléia crônica, aumento progressivo do volume craniano, amaurose e crises convulsivas. Ao exame chamava a atenção a macrocefalia e a amaurose. $O$ aspecto radiológico da hiperostose sugeriu o diagnóstico de meningioma, mas a grande extensão do processo, atingindo tôda a calota craniana, causou estranheza. A angiografia cerebral mostrou apenas aumento da circulação dependente da carótida externa. O crescimento tumoral, sob forma de meningioma em placa, explica porque o processo não foi demonstrado na angiografia. A amaurose foi conseqüência da compressão direta dos nervos ópti$\cos$ e não de hipertensão intracraniana. 
A arquitetura da calota craniana de nosso paciente assemelha-se à descrita por Rowbotham ${ }^{4}$, no tipo que classificou como hiperostose tumoral difusa da calota, com predominância tumoral. Nestes casos a estrutura óssea é inteiramente remodelada, desaparecendo todos os traços de cavidade diplóica e das tábuas ósseas originais, sendo a calota substituida por espículas e colunas dispostas radialmente.

$\mathrm{O}$ exame histológico mostrou aspecto típico de meningioma, sem caracteres de malignidade.

\section{RESUMO}

$\dot{E}$ apresentado caso de extenso meningioma em placa atingindo tôda a convexidade e determinando grande hiperostose da calota craniana. O quadro clínico caracterizou-se por aumento do volume do crânio, cefaléia, déficit de visão e convulsões. As radiografias e o estudo necroscópico mostraram que as tábuas ósseas foram substituidas por espículas dispostas radialmente. $\mathrm{O}$ aspecto histológico, típico de meningioma, não sugeria malignidade.

\section{SUMMARY}

\section{"Meningioma en plaque" involving the entire cerebral convexity}

The case of a patient with hystologically confirmed meningeoma is reported. The tumor extended continuously over the entire cerebral convexity and promoted remarkable hyperostosis of the skull. Headache, blindness, increased skul and convulsions were the main clinical manifestations. The two laminae of the skull were replaced by spikes radially arranged, as suggested by the X-ray picture and confirmed at necropsy. The hystologic aspect of the tumor did not show evidence of malignity.

\section{REFERENCIAS}

1. ALMEIDA LIMA, P. — Meningiomas. In Tumores Intracraneales, S. Obrador A. \& J. Sanz Ibañez. Paz Montalvo, Madrid, 1955, págs. 305-330.

2. CUSHING, H. \& EISENHARDT, L. - Meningiomas. 2a ediçāo, Hafner, New York, 1962.

3. OBRADOR, A. S. - Meningiomas intracraneales. In Tumores del Sistema Nervioso Central, Paz Montalvo, Madrid, 1960, págs. 129-142.

4. ROWBотHAM, G. F. - The hyperostoses in relation with the meningiomas. Brit. J. Surg. 26:593-623, 1936.

Clínica Neurológica - Faculdade de Medicina da Universidade de São Paulo - Caixa Postal 3461 - São Paulo, SP - Brasil. 